\title{
Development of electrode structure for acoustic delay lines by using inject printing method
}

\author{
Andrey Smirnov ${ }^{1, *}$, Iren Kuznetsova ${ }^{1}$, Vladimir Anisimkin ${ }^{1}$, and Vladimir Kolesov ${ }^{1}$ \\ ${ }^{1}$ Kotel'nikov Institute of Radio Engineering and Electronics of RAS, Laboratory of Semiconductor \\ Processes in Semiconductor Materials, 125009, Mokhovaya st., 11 bld.7, Moscow, Russia
}

\begin{abstract}
The results concerning to study of possibility to produce electrode structure of acoustic delay lines by using inject printing method are presented. The investigation of morphologic and structure characteristics of electrode structure produced has been carried out. The possibility of excitation of plate acoustic waves characterized by high value of electro-mechanical coupling coefficient by such acoustic delay lines has been demonstrated.
\end{abstract}

\section{Introduction}

It should be noted that in recent years there has been a surge in interest in the possibility of creating printed electronics in order to improve operational characteristics and expand the functionality of the developed devices [1]. Printing can be performed on both rigid and flexible substrates [2, 3], and can also be used to create three-dimensional structures $[4,5]$. The InkPrint process can be carried out at room temperature while it is potentially suitable for the production of large-area electronic components [6]. This technology makes it possible to create high-performance and simple thin-film solar cells, and it is already used for printing radio-frequency identification tags, components of sensors, antennas, and batteries [7-9]. It is possible to consider InkPrint technology as a replacement for lithographic methods that are widely used in silicon electronics. These methods require a large number of technological steps and they are presented very expensive technology. Ink materials based on metals such as gold $(\mathrm{Au})$, silver $(\mathrm{Ag})$ and copper $(\mathrm{Cu})$ are usually used as materials for InkPrint technology. Some of the most promising materials are Ag nanoparticle inks. This is connected with its resistance to oxidation, good electrical conductivity (one of the highest of all metals) and price (much cheaper than $\mathrm{Au}$ ) [10-13]. This work shows the possibility of using the inkjet printing method to create acoustic delay lines on a lithium niobate substrate.

\section{Objects for investigation and experimental technique}

\subsection{Nano-ink}

Silver nano-ink produced by Akkolab (Moscow, Russia) was used as ink. The viscosity of the ink was $15-25 \mu \mathrm{Pa} \bullet \mathrm{s}$, particle concentration $15-20 \mathrm{wt} \%$ with a size of $10 \pm 2 \mathrm{~nm}$. Figure 1 shows a micrograph of particles.

\footnotetext{
* Corresponding author: andre-smirnov-v@yandex.ru
} 


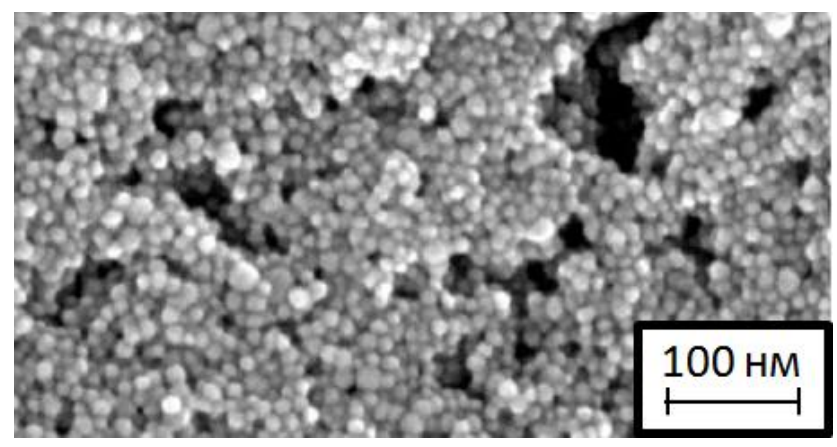

Fig. 1. SEM image of Ag nanoparticles.

\subsection{Sample preparation}

The electrode structures were formed by inkjet printing using a Dimatix DMP-2831 printer (Fujifilm USA), equipped with a piezo-head cartridge with 16 nozzles that emit droplets with a volume of $10^{-9} 1$ or more. To study the possibility of exciting acoustic waves using printed electrode structures delay lines (DL) with IDT parameters calculated for lithium niobate YX were formed on the surface of lithium niobate substrates. The IDT was oriented in the direction of the $\mathrm{X}$ axis. The IDT parameters are presented in Table 1. The aperture of the electrodes, in both cases, was $7.5 \mathrm{~mm}$. The thickness of the substrate was $380 \mu \mathrm{m}$. To remove residual organic solvent, after printing, the resulting structures were annealed at a temperature of $200^{\circ} \mathrm{C}$.

Table 1. Geometric parameters of printed delay lines

\begin{tabular}{|c|c|c|c|c|}
\hline $\begin{array}{c}\text { Crystal } \\
\text { orientation, } \\
\mathrm{LiNbO}_{3}\end{array}$ & $\begin{array}{c}\text { The number } \\
\text { of pairs of } \\
\text { electrodes }\end{array}$ & $\begin{array}{c}\text { Pin width, } \\
\text { mkm }\end{array}$ & $\begin{array}{c}\text { Distance } \\
\text { between } \\
\text { pins, } \\
\text { mkm }\end{array}$ & $\begin{array}{c}\text { Distance } \\
\text { between } \\
\text { IDT, mkm }\end{array}$ \\
\hline $\mathrm{YX}$ & 4 & 300 & 330 & 3030 \\
\hline
\end{tabular}

The Figure 2 shows the delay line pattern (a) and a photograph of the printed delay line (b).
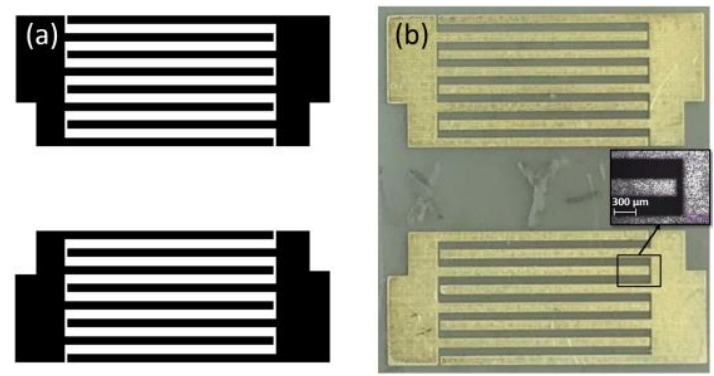

Fig. 2. Patterns of delay lines for lithium niobate crystal orientation YX (a) and corresponding photo with detailed inset (b).

\subsection{Sample characterization}

The morphology of the sample was studied using a scanning electron microscope (SEM) Mira II (Tescan, Czech Republic). The images were obtained using a secondary electron detector. 
The electrophysical properties of printed electrode structures were measured using an Agilent B1500A instrument in combination with a PM-5 probe station (Cascade Microtech).

After printing and annealing the delay lines gold wires with a diameter of $25 \mu \mathrm{m}$ and a length of $30 \mathrm{~mm}$ were glued to the pads using the Silver Print conductive glue (Figure 3 ). This plate was fixed and connected to the four-terminal analyzer E 5061 B (Keysight). Then an alternating voltage of $300 \mathrm{mV}$ was applied to the IDT.

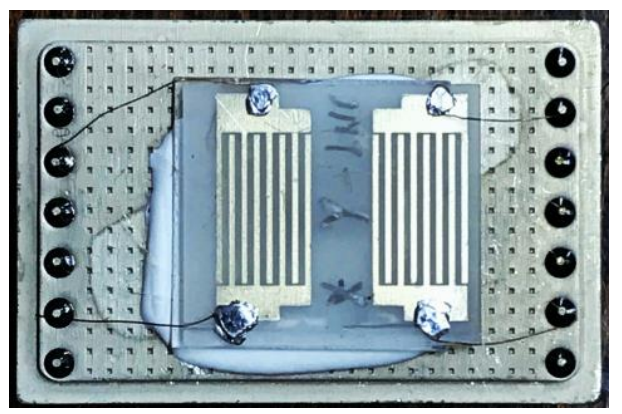

Fig. 3. The photo of ink-printed delay line formed as chip.

\section{Investigation results}

A SEM image of the surface and cleavage of the sample is shown in Figure 4. It can be seen that the electrodes consist of agglomerates of nanoparticles "soldered" to each other, of the size of about $100 \mathrm{~nm}$.
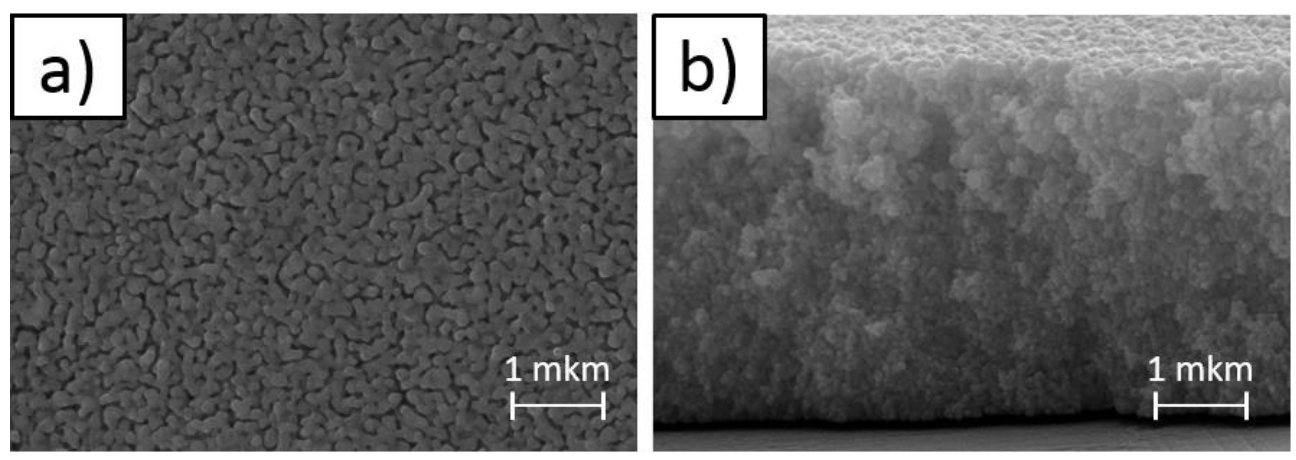

Fig. 4. SEM images of surface (a) and cleavage (b) of the sample.

The resistivity of the resulting electrode structure was $0.59 \mu \Omega \cdot \mathrm{m}$ that is six times higher than the resistivity of the bulk material $(0.104 \mu \Omega \cdot \mathrm{m})$ [14].

Figure 5 shows the frequency dependence of the parameter $S_{21}$ of the produced delay line. It is seen that the created delay line supports the propagation of several types of piezoelectric acoustic waves of zero and higher orders.

Thus, the possibility of using inkjet printing technology to create interdigital transducers (IDT) for the implementation of acoustoelectronic devices on waves in the plates has been demonstrated. It was shown that the resulting printed electrode structure of the delay line makes it possible to excite acoustic signals, including those characterized by low excitation and propagation losses. This study is an important step in creating flexible acoustoelectronic devices. 


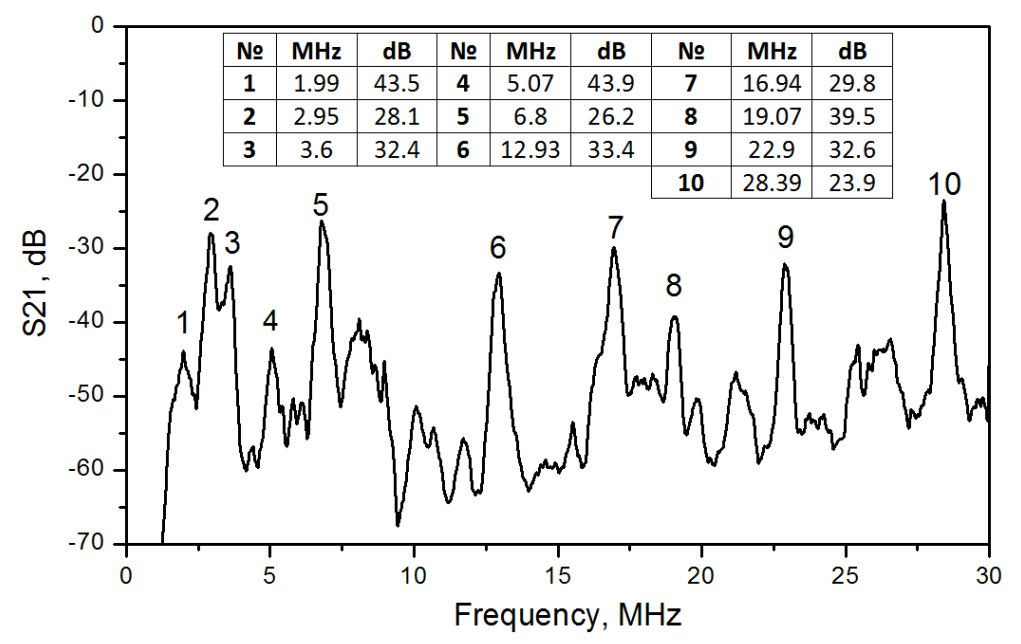

Fig. 5. Frequency dependence of the parameter $S_{21}$ of the delay line based on YX LiNbO3 plate.

Work is supported by the grant \#19-07-00145 from Russian Basic Research Foundation.

\section{References}

1. S. Kirchmeyer, Transl. Mater. Res. 3, 010301 (2016)

2. J. Schneider, P. Rohner, D. Thureja, M. Schmid, P. Galliker, D. Poulikakos, Adv. Funct. Mater. 26, 833-840 (2016)

3. J.U. Park, M. Hardy, S.J. Kang, K.Barton, K. Adair, D.K. Mukhopadhyay, C.Y. Lee, M.S. Strano, A.G. Alleyne, J.G. Georgiadis, P.M. Ferreira, J.A. Rogers, Nat. Mater. 6 (10), $782-789$ (2007)

4. K. Sun, T.S. Wei, B.Y. Ahn, J.Y. Seo, S.J. Dillon, J.A. Lewis, Adv. Mater., 25(33) 4539-4543 (2013)

5. B.W. An, K. Kim, H. Lee, S.Y. Kim, Y. Shim, D.Y. Lee, J.U. Park, Adv. Mater. 27(29) 4322-4328 (2015)

6. S. Wünscher, R. Abbel, J. Perelaer, U.S. Schubert, J. Mater. Chem. 2(48), 1023210261 (2014)

7. T.M. Eggenhuisen, Y. Galagan, A.F.K.V. Biezemans, T.M.W.L. Slaats, W.P. Voorthuijzen, S. Kommeren, S. Shanmugam, J.P. Teunissen, A. Hadipour, W.J.H. Verhees, S.C. Veenstra, M.J.J. Coenen, J. Gilot, R. Andriessen, W.A. Groen, J. Mat. Chem. 3(14), 7255-7262 (2015)

8. A. Salim, S Lim. Sensors 17(11), 2593 (2017)

9. A. Lesch, S. Maye, M. Jovic, F. Gumy, P.Tacchini, H.H. Girault, Biotech, Biomater. Biomed.: Tech Connect Briefs. 3, 121-124 (2016)

10. D.V. Leff, P.C. Ohara, J.R. Heath, W.M. Gelbart, J. Phys. Chem. 99(18), 7036-7041 (1995)

11. D. Huang, F. Liao, S. Molesa, D. Redinger, V. Subramanian, J. Electrochem. Soc. 150(7), G412-G417 (2003)

12. S. Magdassi, A. Bassa, Y. Vinetsky, A. Kamyshny, Chem. Mater. 15(11), 2208-2217 (2003)

13. S. Magdassi, M. Grouchko, A. Kamyshny, Mater. 3(9), 4626-4638 (2010)

14. G.T. Meaden, Electrical Resistance of Metals (Springer, New York, 1965) 